[Forthcoming: 2014. International Journal of Economics and Economic Policy. 11:29-47. DOI: $10.1007 / \mathrm{s} 10368-013-0245-8]$

\title{
The Emergence of Next Generation Internet Users
}

\author{
William H. Dutton and Grant Blank \\ Oxford Internet Institute \\ University of Oxford
}

\begin{abstract}
The Internet is central to the new media, but the Internet is itself a dynamic technology that is constantly evolving as users adopt and reject new features, devices and applications and use them in ways that are often unanticipated. This article is anchored in longitudinal survey data on how Britons use the Internet, which illuminates the emergence of new patterns of accessing the Internet over multiple devices — some of which are portable — in everyday life and work. We call those who adopt this new approach ' next generation users '. In contrast, first generation users remain anchored to one or more personal computers in the household or workplace for accessing the Internet. The analysis shows how this emerging pattern of access is reshaping the use and impact of the Internet, such as in supporting the production of user generated content. The analysis also shows how next generation access is socially distributed; creating a new digital divide that reinforces socioeconomic inequalities. Future research needs to move beyond the study of access to the Internet to track the diffusion of next generation access and its implications across a wider array of nations.
\end{abstract}




\section{Introduction}

That we have entered a "post-PC" era is a common perception. The basis for this perception are arguments like "more and more consumers are using their mobile devices as their 'default gateway' for accessing the Internet” (King 2012), or “As soon as three to five years from now, the average business professional will be transitioning from 'Heavy' clients such as desktop PCs and business laptops with large amounts of localized storage and localized applications ... to very small and extremely power efficient, ... systems ... which will function mostly as cache for applications that run remotely" (Perlow 2012). HewlettPackard's September 2012 announcement that it would lay off 29,000 employees seemed to support this argument with hard data on the decline of the personal computer. There is no question that the phenomenal growth of smart phones, tablets and readers is having a major impact on how people access the Internet. However, the arguments favoring the "post-PC" era are based on the assumption that PCs are being supplanted by light-weight, mobile devices. While PC sales are slowing as the market matures the assumption that PCs are being superceded lacks supporting evidence.

Mobile devices offer new kinds of access to the Internet but, as we shall show, the relationship between PCs and mobile devices is a great deal more complex than simple replacement of one device by another. As we describe the relationship between PCs and mobile devices we will answer several questions: How have these new devices changed the way people access the Internet? What differences might they make in relation to how people use the Internet, such as for various entertainment or information services? Who uses these devices? Are they closing down the Internet, making it less creative, or opening up the Internet to new users and uses? If they are valuable new channels for access, are they more widely accessible, enabling new users, or does access on new devices reinforce existing digital divides? 


\section{Theoretical Perspectives}

Several theoretical perspectives bear on the social implications of a shift in patterns of access to the Internet. They are all qualitative explanations of patterns of relationships, rather than operationally defined models, but they capture the major competing perspectives on the role of the Internet in everyday life.

\section{Technical Rationality}

The technical rationality perspective draws on major features of new technologies to reason about the likely implications of adoption. While many social scientists view this as a technological determinist perspective, it characterizes some of the most prominent scholars of the Internet and new technology, such as Lawrence Lessig (1999) and his view that 'code is law'. ${ }^{1}$ The view from this perspective is that the move towards 'appliances' is bound up with adoption of closed applications or "apps" that have a limited set of functions. They restrict the openness, and 'generativity' of the Internet, compared to general-purpose personal computers, which enable users to program, write code, and not be limited to a secured set of applications and sites (Zittrain 2008). Since those who adopt the new appliance devices, such as tablets, are satisfied with the closed applications, they are likely to be less sophisticated that those who remain anchored to personal computing, and less creative in their use and application of the Internet. Will they move users toward to a role as passive browsers of information and consumers of entertainment?

\section{Domestication: A Social Rationality}


In contrast, there is a more socially determinist perspective on the social role of the Internet and related information and communication technologies (ICTs) in the household that is best captured by work on the 'domestication' of the Internet. Domestication (Haddon 2006, 2007, 2011; Silverstone et al. 1992) emphasizes the influence of households or work places on shaping, taming or domesticating technologies as users fit them into the values and interests of their particular social context. People adopt and integrate technologies into their everyday routines in ways that follow and reinforce existing practices, which differ across households.

The concept of domestication was developed as a way to elaborate a conceptual model for exploring the role of ICTs on life within the household (Silverstone et al 1992, and Livingstone 1992; and Silverstone 1996). The formulation suggests that four "non-discrete elements" constitute the domestication process, called: appropriation, objectification, incorporation, and conversion (Silverstone et al 1992: 20). Appropriation occurs when the technology product is purchased and its entry into a household must be managed.

Objectification refers to the location of a technology in the household, both physically and symbolically. Incorporation is when the technology is fitted into everyday routines of a household. Finally, conversion designates the ways in which technologies are displayed to others for impression management. ${ }^{2}$ These elements do not have a strict order. Although appropriation is clearly prior, the other three elements interact and shape each other.

This paper is particularly interested in the incorporation of the Internet into daily routines of the people as they appropriate the technologies of mobile devices and incorporate them into their everyday routines. Characteristic of the Internet is that it is not a single new technology. Rather it gives access to a variety of innovations, including web browsers, location and 
direction services, email and social networking. This presents a large menu of items to be incorporated into people's day-to-day life. It will not be done all at once; for many the Internet is a continuing, multi-year exploration of new possibilities.

This domestication model is consistent with earlier conceptions of the social shaping of technology in organizations, such as the notion of 'reinforcement politics', which argued that organizations adopt and shape information technologies to follow and reinforce the prevailing structures of power and influence within the adopting organizations (Danziger et al. 1982). Since domestication suggests people shape the Internet to their pre-existing interests and values, we would not expect the adoption of new mobile devices to make much difference in how people use the Internet, nor have a significant, transformative impact on the social role of the Internet in their lives.

\section{Reconfiguring Access}

A different theoretical perspective revolves around the concept of 'reconfiguring access' (Dutton 1999; 2005). From this perspective, it is impossible to determine the implications of technologies in advance, either by rationally extrapolating from the technical features of the innovations or by assessing the interests and values of users. This distinguishes this perspective from both a more technologically determinist view and a socially determinist position. Reconfiguring access takes note of the fact that users often reinvent technologies, employing them in ways not expected by their developers. In addition, the social role of a technology can be influenced by the actions of many actors other than users, and from choices far outside the household, which distinguishes this perspective from the notion of domestication. Control of new technologies, particularly a networked technology such as the 
Internet, is distributed across a wide array of actors, including users, Internet Service Providers, hardware manufacturers, search engine, and social networking companies. Rather than expecting the impacts to be determined by features of the technology, or the values and interests of the household, reconfiguring access places a central emphasis on observing the actual use and impact across a diversity of users to discern emergent patterns of use and impact.

However, like a more technological determinist model, the concept of reconfiguring access is based on the expectation that technologies do matter - they have social implications - in two major respects. They reconfigure (1) how people do things, as well as (2) the outcome of these activities. People adopt and use technologies, such as the Internet, more or less intentionally to reconfigure access in multiple ways, including their access to people, information, services and technologies, and access to themselves. From this perspective, the technology does not simply fit into existing practices, but it changes them. If a person enjoys reading the newspaper, they might decide to use the Internet to get access to the news. However, this changes how they get the news and how much news they can get, as well as what news they obtain and how easily they obtain it. It reconfigures their access to the news, in this case.

The Internet can change the outcome of information and communication activities by virtue of changing cost structures, creating or eliminating gatekeepers, redistributing power between senders and receivers, making a task easier or more difficult, changing the circumstances under which a task can be performed, restructuring the architecture of networks (many to one versus one to many), and changing the geography of access. By changing costs, or eliminating gatekeepers, for example, the Internet can reconfigure access to information, 
people, services, and technologies, such as by making millions of computers accessible to a user of a smart phone.

The ability of the Internet to reconfigure access can be used to reinforce existing social arrangements, like helping friends stay in touch, or to reconfigure social relations, such as helping a person to meet new people. It can be used to reinforce a person's interest in the news, but also open up new channels and sources for news.

The main methodologies used to study domestication have been qualitative, usually ethnographic (Silverstone 2005). This paper uses survey data, but in a qualitative manner, which has certain disadvantages because it cannot address questions of meaning in the ways than an ethnographic approach seeks to do. However, others have used surveys to study domestication (e.g. Punie 1997), and a sample survey has the major advantage that the results can be generalized to a population. In this case, we can generalize to the British population and speculate on the wider applicability of our findings.

\section{Methods and Data}

This paper addresses these issues around new patterns of Internet access by focusing on the analysis of survey data gathered in Britain as part of the Oxford Internet Survey (OxIS), which is one component of the World Internet Project (WIP), a consortium of over two dozen national partners. OxIS began in 2003 and has been organized around a number of themes that allow us to analyse the dataset for specific trends and topics, including: digital and social inclusion and exclusion; shaping, regulating and governing the Internet; safety, trust and privacy online; social networking and entertainment; and online transactions and commerce. Based on the demographic and attitudinal questions asked in the survey it is possible to 
construct profiles of the survey participants, which include users and non-users of the Internet. Our analyses relate these profiles to the data about use and non-use to allow us to draw detailed conclusions about who uses the Internet, in which ways, and to what extent.

OxIS is a biennial sample survey of adult Internet use in Britain, including England, Wales, and Scotland. ${ }^{3}$ The first survey was conducted in 2003 and subsequent surveys followed in 2005, 2007, 2009 and 2011. Each survey has followed an identical sampling methodology. The respondents are selected for face-to-face interviews based on a 3-stage random sample of the population. Professionally trained field survey staff conduct face-to-face interviews in people's homes. The data are then weighted based on gender, age, socio-economic grade, and region. Response rates using this sampling strategy have been very high: $60 \%$ in $2003,66 \%$ in $2005,68 \%$ in $2007,53 \%$ in 2009 , and $51 \%$ in $2011 .{ }^{4}$ Although questions have been added as new issues emerged, many questions have remained the same to facilitate comparisons between years.

An important strength of OxIS is that it is not a convenience sample. This distinguishes it from many otherwise excellent datasets. This has both methodological and theoretical implications. Methodologically, as a representative sample, OxIS allows us to project to the adult (14 and over) population of Britain. This is not possible for a convenience sample. Theoretically a random sample of adults allows us to explore a number of interesting variables. The convenience samples are often composed of college students who have limited variation in age, social status, and income compared to the general population of Internet users. We can explore the effects of these demographic variables where convenience samples cannot. 
We use the 2011 survey, which contains completed interviews with 2,057 respondents. Our analyses are based either on the full sample of 2,057 or on the subset of current Internet users: 1,498 respondents, $72.8 \%$ of the full sample. ${ }^{5}$ However, while the focus of our analysis is on a snapshot of one nation, as part of the WIP we are able to compare our findings with the results in nations around the world to determine of our findings are more or less consistent. Our analysis was innovative within the WIP collaboration, meaning that our exact analysis has not been replicated in other countries, but we have found no reports from our partner countries that would suggest the UK findings are unique in the patterns we discuss. The main differences are in levels, such as the level of Internet adoption, but not in the basic patterns of relationships that we report.

\section{The Emergence of Next Generation Users}

In 2011, along with trends in mobile phone use and the diffusion of appliances, such as tablets, we saw two dramatic and interrelated shifts appearing in our survey results. First, there has been a continuing increase in the proportion of users with portable devices, using the Internet over one or another mobile device, such as a smart phone. In 2003 this was a small proportion. At that time, $85 \%$ of British people had a mobile phone but only $11 \%$ of mobile phone users said they accessed email or the Internet over their mobile phone. By 2009, 97\% of British people owned a mobile phone, and the proportion of users accessing email or the Internet over their phone doubled to $24 \%$ - albeit still a minority of users. In 2011, this increased to nearly half (49\%) of all users. By 2011, the mobile phone became one of a number of devices for accessing the Internet that are portable within and outside the household. 
Secondly, Internet users often have more devices, such as multiple computers, readers, tablets, and laptop computers, in addition to mobile phones, to access the Internet. In 2009, only 19\% had a PDA (Personal Digital Assistant). Since then, the development of readers and tablets has boomed, such as with Apple's successful introduction of the iPad. The very notion of a PDA has become antiquated. In 2011, almost one-third of Internet users had a reader or a tablet with $6 \%$ having both devices. Fully $59 \%$ have access to the Internet via one or more of these multiple devices other than the household personal computer.

Most observers have treated these developments as separate trends. There are even academics who focus only on mobile communication, and others who focus on tablets or the use of smart phones. ${ }^{6}$ However, these two trends are not just related but are also synergistic. Those who own multiple devices are also more likely to use the Internet on the move and from multiple locations.

Based on this analysis we identified two categories of users. First, we define the Next Generation User (NGU) as someone who accesses the Internet from multiple locations and devices. Specifically, we operationally define the next generation user as someone who uses at least two Internet applications (out of four applications queried) ${ }^{7}$ on their mobile and who fits two or more of the following criteria: they own a tablet, own a reader, own three or more computers. By this definition, in 2011, almost a third of Britons, and $44.4 \%$ of Internet users in Britain, were Next Generation Users (Figure 1 and Figure 2).

Second, from the Oxford Internet Institute's (OII) first survey of Internet use in 2003, and in line with most other developed nations, access has been based primarily on the use of a personal computer in one's household, linked to the Internet through a modem or broadband 
connection. For many, this was complemented by similar access at work or school. The major change in access since 2003 was the move from narrowband dial-up to broadband always-on Internet connections. By 2009, nearly all Internet users had a broadband connection, increasingly including wireless connections within the household, such as over a WiFi router. While speeds will continue to increase through initiatives such as 'superfast' broadband, and wireless connections will expand, this pattern of Internet access characterizes the 'first generation user' in Britain.

Next generation users are not just teenagers: as a consequence of long-term trends in patterns of use they emerged across all age groups. They did not appear overnight: with the benefit of hindsight, we can look back and see that the proportion of next generation users among Internet users grew from $20 \%$ in 2007, to $32 \%$ in 2009, to $44 \%$ in 2011 (Figure 1).

[g0a8-ngu.wmf]

\section{Figure 1: Next Generation Internet Users}

100

80

60

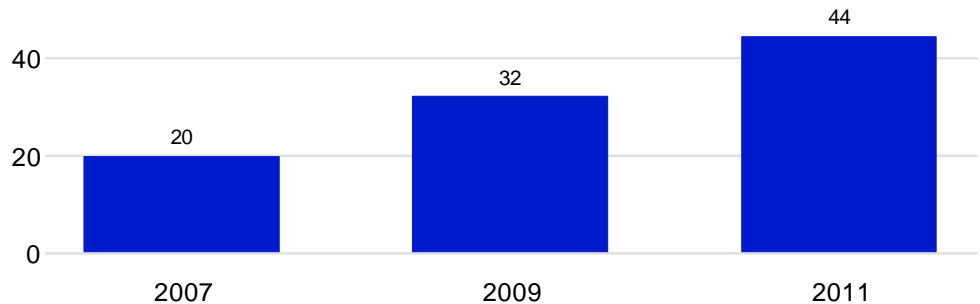

2007

2009

2011

Current users. OxIS 2007: $\mathrm{N}=1,578$; OxIS 2009: $\mathrm{N}=1,401$; OxIS 2011: $\mathrm{N}=1,498$

Figure 2 shows the rise Next Generation Users in the context of overall Internet use. British Internet use grew from just under 60\% in 2003 to $73 \%$ in 2011, leaving more than a quarter of the British population without access to the Internet. There has been a steady but slow decline in the proportion of people who have never used the Internet (non-users), and relative 
stability in the proportion of those who have used the Internet at one time but who no longer do so (ex-users). Despite multiple government and private initiatives aimed at bringing people online, digital divides remain in access to the Internet. The slow growth in the proportion of British people with access to the Internet contrasts dramatically with the rapid rise of Next Generation Users. They increased from $13 \%$ to $32 \%$ of the British population by 2011. There is a corresponding decline in First generation users from $54 \%$ to $40 \%$ of the British population. Clearly, the promotion of new technical devices, such as the tablet, has changed the way households access the Internet. It is hard to see this as simply a process of domestication, rather than a consequence of new product and service offerings.

[g0a7-ndvx.wmf]

\section{Figure 2: Next Generation Internet Users in Context}

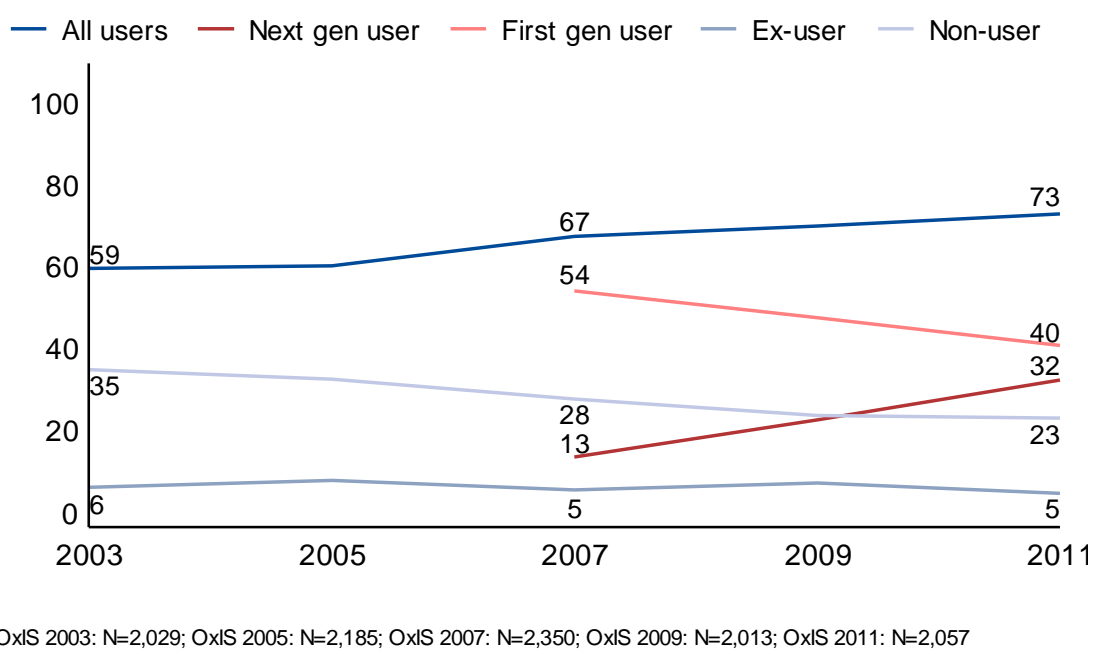

We will contrast the characteristics of First Generation and Next Generation Users in the coming pages. But first, how can we explain the rise of the Next Generation User, and its significance, in the context of the study of the Internet? 


\section{Why Does this Matter?}

The following pages show how this transformation in Internet access is linked to important changes in patterns of use, and in the social implications of use. We then show that Next Generation Users are not evenly distributed, but have higher incomes, indicating a new digital divide in Britain and most certainly in other nations.

How individual users access the Internet shapes the ways in which they use the technology, and how people wish to use the Internet is shaping the technologies they adopt. This is shown by the contrast between first and next generation use of the Internet in three areas: content production, entertainment and leisure, and information seeking. In each case, a technical rationality might see innovations reducing the openness and generativity of users, while from a domestication perspective, you would expect to see little change in patterns of use between next and first generation users.

\section{Content Production}

In contrast to the technical rationality, with its focus on how the limited openness of new devices restricts users, next generation users are more likely to be producers of content than are first generation users, who concentrate more on consumption rather than production. For many types of content, next generation users are as much as 25 percentage points more likely to be producers. Specifically, next generation users are more likely to update or create a profile on a social networking site (Figure 3). They are also more likely than first generation users to post pictures and videos, post messages on discussion boards or forums, and post stories, poetry or other creative work (Figure 3). For more demanding types of content, such as maintaining a personal website or writing a blog, next generation users are almost twice as likely to be producers than are first generation users. Innovations are reconfiguring access by 
enabling greater production of content by next generation users, but in a direction opposite to that expected on the basis of the more limited features of appliances.

[g0a3-pdn.wmf]

\section{Figure 3: Next Generation Users by Content Production}

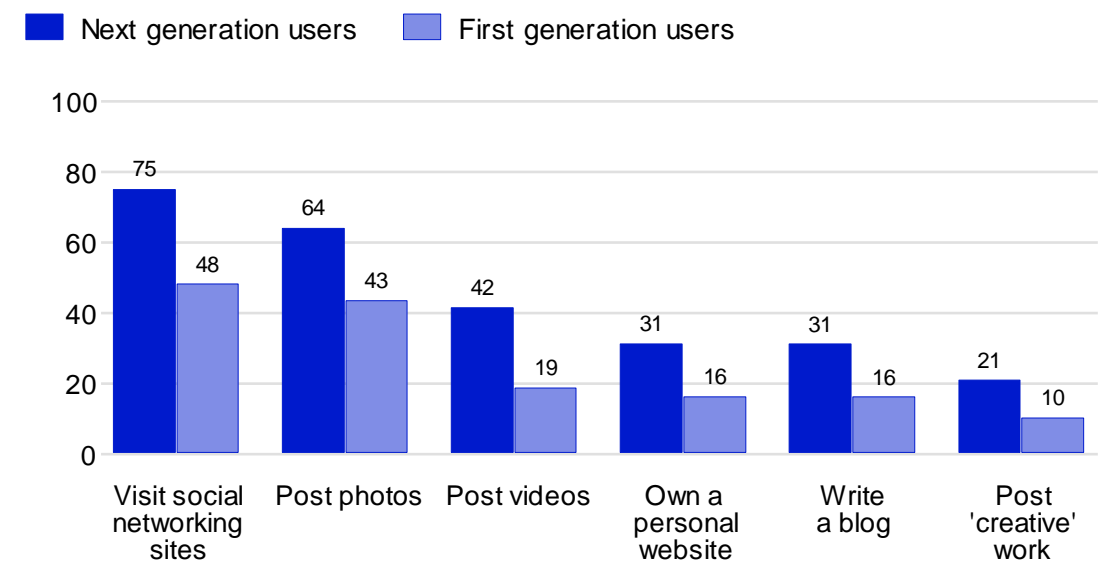

Current users. OxIS 2011: $\mathrm{N}=1,498$

\section{Entertainment and Leisure}

Compared with first generation users, the NGU is much more likely to listen to music online, play games, download music, watch videos online, and download, as well as upload, videos or music files (Figure 4). As with content production, these are large differences, often exceeding 20 to 25 percentage points. NGUs are also more likely to bet or gamble online, but this difference is much smaller than with content production. Next generation users seem to have integrated the Internet more extensively into their entertainment and leisure activities. In this respect, an association with listening to more music or watching more video productions is in line with the technical rationality of appliances, but still reconfiguring access in significant respects, which would not be anticipated from the perspective of domestication. 
[g0a2-ent.wmf]

\section{Figure 4: Next Generation Users by Entertainment}

\section{and Leisure}

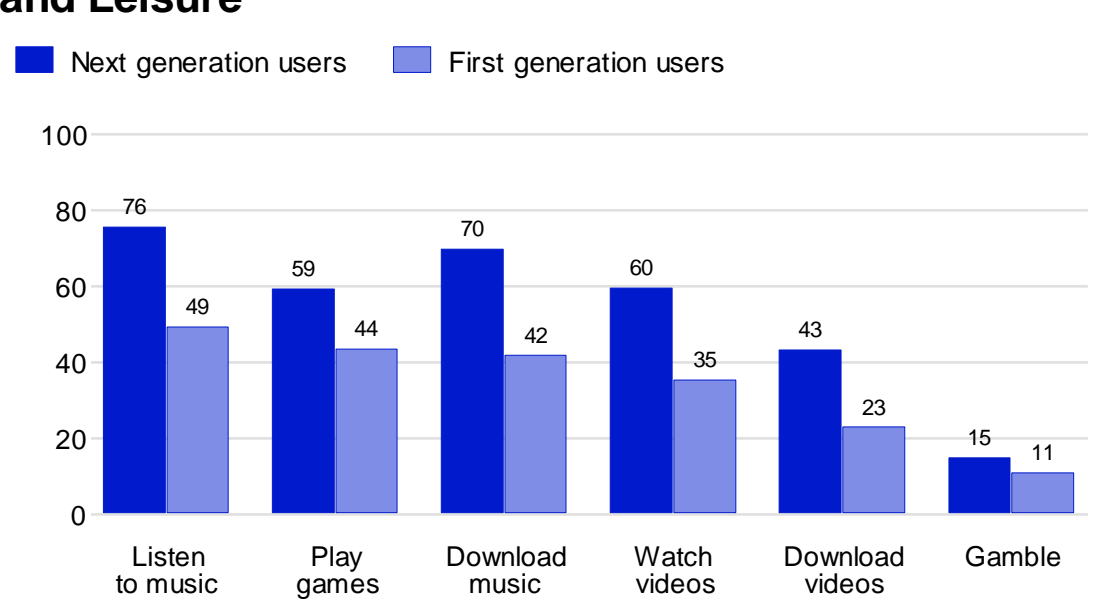

Current users. OxIS 2011: $\mathrm{N}=1,498$

The essential importance of the Internet

Next generation uses are much more likely to agree that the Internet is "essential". Figure 5 reports the percentage that considers various media essential for information, Figure 6 reports for entertainment. Both figures tell a consistent story about next generation users. For information, they are 16 percentage points more likely to consider the Internet essential; for entertainment, they exceed first generation users by 10 percentage points. Also notable is that the Internet is the only medium where next generation and first generation users differ, except for spending time with other people for entertainment. These figures underline the disproportionate value that next generation users place on the Internet.

[g0a9-nfx.wmf] 


\section{Figure 5: Importance of Media for Information}

Next generation users $\quad \square$ First generation users $\quad \square$ Non- and Ex-users

100

80

60

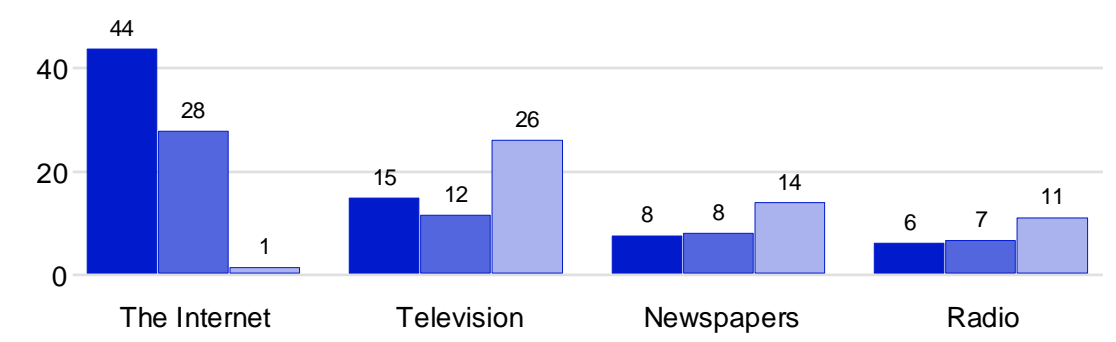

OxIS 2011: N=2,057

[g0a10-entx.wmf]

Figure 6: Importance of Media for Entertainment

Next generation users $\square$ First generation users $\quad \square$ Non- and Ex-users

100

80

60

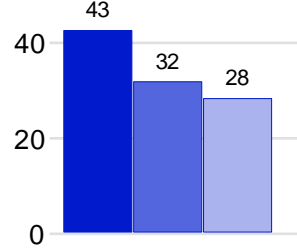

Spending time with other people

OxIS 2011: $\mathrm{N}=2,057$

\section{Information Seeking}

As interesting as how next generation users differ from first generation users is how they are similar. One of the major changes over the past decade has been the growing use of the Internet as a source of information, particularly with the rise of powerful and usable search engines such as Google. All Internet users increasingly go to the Internet for information. It is their first port of call. However, next generation users are more likely than first generation users to go to the Internet first for all kinds of information (Figure 7). 
For example, $84 \%$ of next generation users go online for news, compared with $75 \%$ of first generation users. The differences here are smaller than the differences observed above for content production and entertainment, only 7 to 14 percentage points, but statistically and substantively significant. The largest difference is looking for sports information. Since sports are an entertainment activity, they have much in common with entertainment uses (Figure 4). Sport is the exception that proves the rule. Given that next generation users can access the Internet from more locations on more devices at more times of the day, it might be surprising that their use of the Internet for information is not more extensive. One major reason is that information seeking has become so common for all users.

[g0a4-nfo.wmf]

\section{Figure 7: Next Generation Users by Information}

\section{Seeking}

Next generation users $\square$ First generation users

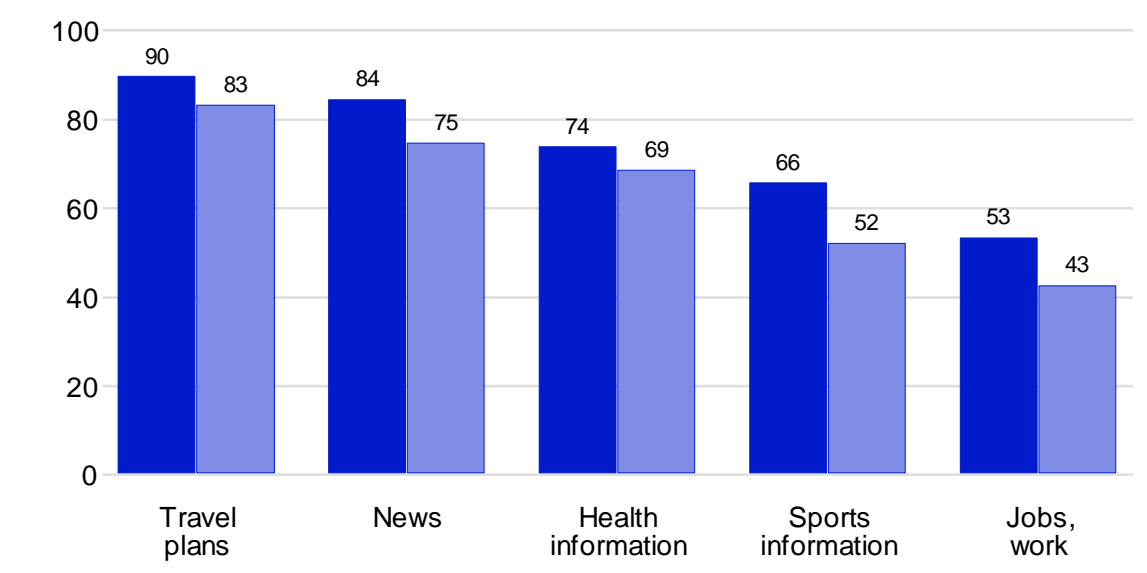

Current users. OxIS 2011: $\mathrm{N}=1,498$

Portability and Mobility

Do next generation users access the Internet from more locations? Figure 8 shows that this is indeed the case. NGUs are no more likely than first generation users to access the Internet 
from their home, but - importantly - they are no less likely to do so. This underscores the continuing centrality of the household across the generations of users. However, NGUs are far more likely to access the Internet on the move and from all other locations, including another person's home, at work, at school or at university, at a library, or at an Internet café (Figure 8).

This finding might suggest the flaw in a technically rational argument that appliances would undermine the generativity of the Internet (Zittrain 2008). Appliances are generally not substituting for personal computers and other more general-purpose devices, but complementing these technologies, and extending them in time and place. Nearly everyone with a reader or tablet tends to use these technologies to augment rather than replace their other modes for accessing the Internet.

More generally, and in contrast the technical argument, or the domestication thesis, next generation users appear to be empowered, relative to the first generation users, in creating content, enjoying entertainment online, and accessing information in ways and at times and locations that fit into their everyday life and work in a more integrated way. Of course, those who want to create content and embed the Internet in more aspects of their everyday life are more likely to adopt mobile technologies, so in that sense, a domestication process could be relevant. Through the social shaping of adoption and the empowerment of users, it is clear that the next generation user has a more advantageous relationship with the Internet and the resources it can provide for accessing information, people, services, and other technologies. 
[g0a6-locx.wmf]

\section{Figure 8: Next Generation Users by Locations}

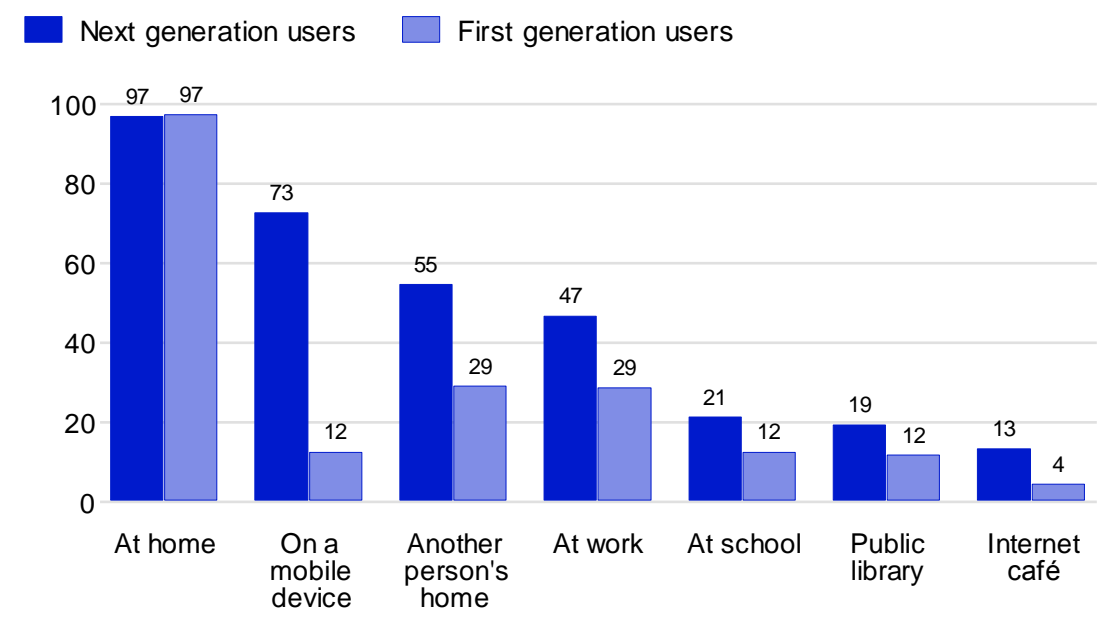

Current users. OxIS 2011: $\mathrm{N}=1,498$

This leads to the question, who are the next generation users? Who is empowered by next generation access, and who is not?

\section{Who are Next Generation Users?}

Are next generation users simply the youth of the Internet age? Not really. Age and life stage are related to next generation use, but primarily in the degree that people who are retired or of retirement age are much less likely to be next generation users. Those who are unemployed are also somewhat less likely to be part of the next generation, while students and the employed are equally likely to be next generation users. It is not simply a function of youth or age cohorts. For example, only $52 \%$ of students are next generation users (Figure 9). In short, domestication is not equal as some are more capable of bending new technologies to serve their needs and interests than are others. In this way, innovations are reconfiguring access by creating a new digital divide across people at different stages of life. 
[g0a5-lif.wmf]

\section{Figure 9: Next Generation Users by Lifestage}

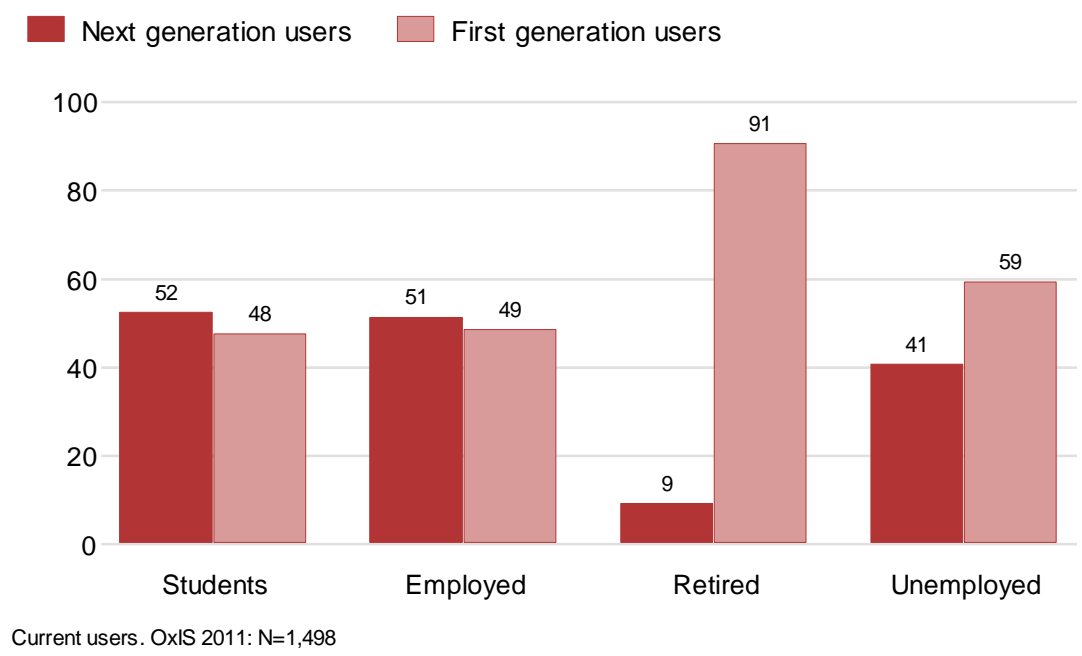

Another major factor related to next generation users is household income. There are next generation users at every income level, but there are clearly a greater proportion of next generation users among the higher income groups in Britain (Figure 10). It helps to have more money when buying a variety of devices, many of which remain expensive. The next generation user is creating a new level of access to the Internet and the Web that supports active patterns of information production and the integration of the Internet into everyday life and work. It creates a new cost for the Internet and is more accessible to the more well-to-do, suggesting that there is a new digital divide developing in Britain, and probably other nations, between the first generation users and the next generation users identified in this report. ${ }^{8}$ 
[g0a1-inc.wmf]

\section{Figure 10: Next Generation Users by Income}

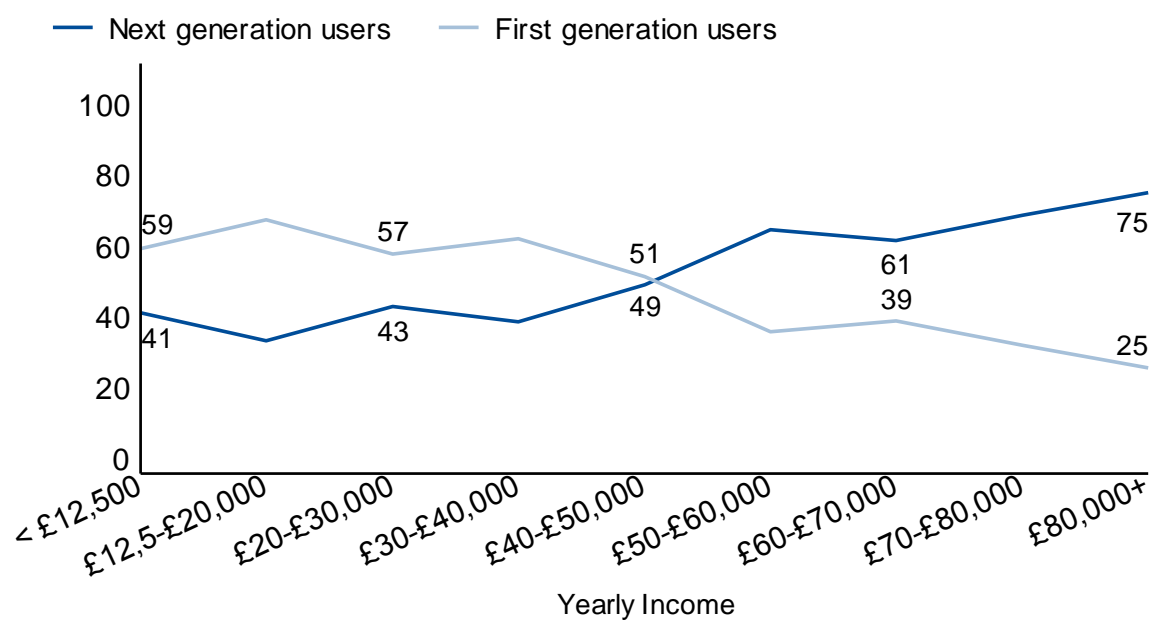

Current users. OxIS 2011: $\mathrm{N}=1,498$

\section{Who are Next Generation Users: Beyond Bivariate Graphics}

The bivariate plots in the previous section informatively describe key demographic characteristics of Next Generation Users. We would like to develop a more sophisticated understanding of Next Generation Users. This requires two steps. First we will describe variables that influence Next Generation Use beyond demographics. And second, we will summarize the characteristics of next generation users in a more concise fashion using a multivariate analysis.

Four categories of non-demographic variables relate to Next Generation Users, beginning with experience on the Internet. Dutton \& Shepherd (2006) and Blank \& Dutton (2011) find that the Internet is an "experience technology", meaning the more people are exposed to the Internet, the more they understand what it can do and the more they use it. People with more experience are more likely to be open to investing in new technologies for accessing the Internet because they are more likely to understand its possibilities and want to explore them in more depth. OxIS contains several items relating to experience. Two items are number of 
years on the Internet and self-rated ability, named "technical ability". Experience could also be negative experiences. Bad experiences on the Internet could influence willingness to engage in Next Generation User activities. OxIS asks about six possible bad experiences on the Internet: SPAM, viruses, misrepresented purchases, stolen identity, requests for bank details, and accidentally reaching a porn web site. Each variable is a yes-or-no, dichotomous variable. We summed these variables to produce a "bad experiences" index, with values ranging from 0-6.

Second, willingness to buy and learn how to use more devices can be influenced by users broad dispositions toward technology. These attitudes represent broad receptiveness to learning and using new technology. As general dispositions they represent the default point of view for people who are using the Internet. Their default point of view may be modified by their personal experiences or other factors. Nonetheless, when people are asked about technology these attitudes are the responses that they give 'off the top of their heads' (Zaller 1992). As the default perspective they influence the willingness of respondents to learn how to use new technologies and the motivation to overcome problems. To this extent, they influence interest in becoming a Next Generation User.

To measure general attitudes toward technology we created indices with the aid of a PCA. Technology attitudes were composed of responses to likert-scaled items: openness to trying new technology, technology is making things better, plus three reverse-coded items; it is easier to do things without technology, lack of trust in technology, and nervousness around technology. The PCA had a single dominant component and the five-item index (called “technology attitudes") has a satisfactory Cronbach's alpha of 0.82 . Note that none of the technology attitude items mention specific aspects of the Internet such as credit cards, 
product quality, trust, shopping, or accuracy of information; they are very general. The concept that this variable measures does not necessarily reflect any deep-seated conviction; instead we see it as general orientation or default point of view toward technology (Zaller 1992).

Confidence in ability to do things on the Internet can also influence willingness to buy new technology. More confident people will be more likely to be willing to invest in new devices because they feel better able to learn how to use the technology. Five OxIS variables ask about confidence: confidence participating in an online discussion, confidence making new friends online, confidence downloading music, confidence uploading photos and confidence in learning new technology. A principal components analysis (PCA) of these variables showed that they formed a single factor and Cronbach's alpha was 0.90 . We summed these items to create a new continuous variable measuring "Web confidence".

Finally, much interaction with smartphones and tablets is via apps. Many apps may require revealing personal details about yourself-like your name and email address — that could allow companies to identify you and market products to you. Some may wish to keep these details private. The extent to which people see this as risky may influence the perceived attraction of mobile devices and, hence, willingness to buy the devices required to become a Next Generation User. Five items ask about comfort revealing personal information: Comfort revealing an email address, a postal address, a phone number, a date of birth or a name. A PCA indicated that these also formed a single factor with a Cronbach's alpha of 0.88 so we again used the factor scores to create a measure called "personal data comfort". 


\section{A Multivariate Understanding of Next Generation Users}

We can describe the characteristics of Next Generation Users using demographic variables available in the OxIS 2011 dataset. The seven variables include age in years, household income, higher education degree, gender, retired, use of the Internet at work, and married. ${ }^{9}$ This model includes all of the demographic variables that we have available in the OxIS 2011 dataset.

In general the demographic results in Table 1 are not surprising; they are largely similar to, and reinforce, the bivariate results shown in previous Figures. The results show that the strongest variable is retired respondents; only $9 \%$ of them are next generation users compared to $49.3 \%$ of non-retired users (see also Figure 9). ${ }^{10}$ The next strongest variables are having a higher education degree and using the Internet at work. The next generation user activities, like content production and entertainment uses, require particular skills. Content production requires certain abilities; for example, writing a successful blog requires the ability to write interestingly and persuasively. These sorts of persuasive literary skills are most common among people with more schooling, especially a university degree. Using the Internet at work usually indicates a more complex job, possibly managerial or professional, and probably

indicates more experience with the Internet (Dutton and Blank 2011). ${ }^{11}$ The concept of domestication suggests that we would find a more equivalent process across households, but clearly, some individuals and households are better placed to take advantage of technical innovations, and in that way, they are reconfiguring who has access to technologies that can support their needs and interests. 
[ngu02.do]

Table 1: Logistic Regression Predicting Next Generation User

\begin{tabular}{|c|c|c|c|c|}
\hline \multirow[b]{2}{*}{ Variable } & \multicolumn{2}{|c|}{ Demographic variables } & \multicolumn{2}{|c|}{ Attitudes \& skills } \\
\hline & Odds ratio & p-value & Odds ratio & p-value \\
\hline Age & 0.96 & 0.001 & 0.97 & 0.000 \\
\hline Income & 1.20 & 0.001 & 1.20 & 0.000 \\
\hline Higher education degree & 1.51 & 0.011 & 1.26 & 0.185 \\
\hline Gender & 0.76 & 0.051 & 1.10 & 0.554 \\
\hline Retired & 0.41 & 0.022 & 0.40 & 0.026 \\
\hline Married & 0.71 & 0.033 & 0.80 & 0.181 \\
\hline Use Internet at work & 1.51 & 0.011 & 1.16 & 0.405 \\
\hline Technology attitudes & & & 1.11 & 0.000 \\
\hline Web confidence & & & 1.05 & 0.004 \\
\hline Personal data comfort & & & 0.98 & 0.246 \\
\hline Bad experiences & & & 1.21 & 0.002 \\
\hline Internet ability & & & 1.23 & 0.082 \\
\hline Years of Internet use & & & 1.03 & 0.018 \\
\hline Constant & 2.31 & 0.001 & 0.05 & 0.028 \\
\hline $\mathrm{N}$ & 1,076 & & 1,036 & \\
\hline McFadden's $\mathrm{R}^{2}$ & $15.3 \%$ & & $21.6 \%$ & \\
\hline Correctly classified & $69.8 \%$ & & $73.5 \%$ & \\
\hline
\end{tabular}

The multivariate analysis indicates that being married reduces the likelihood of being a next generation user. This may reflect the fact that many next generation user activities are timeconsuming activities that often cannot be shared. Married people may have other priorities for their time and prefer to do things together. The coefficient for gender says that women are less likely to be next generation users than men. The centrality of the Internet in the household has been associated with a narrowing of the digital divide. It might well be that the diffusion of more mobile devices that can be integrated into everyday life and work are reconfiguring gender divides to some degree.

Expanding beyond demographic variables to attitudes and skills, we find that two of three attitude variables are significant: general technology attitudes and web confidence; personal data comfort is not significant. Attitudes and web confidence are both positive, as expected. 
The lack of significance for personal data comfort is interesting because mobile devices are most useful when used with various subscription services or for buying content, like books or music. One might have expected Next Generation Users to be more sensitive to the dangers of fraud or theft of personal data. The three skills variables also show a mixed effect. Number of bad experiences and years of Internet use are significant, while self-rated Internet ability is not significant. The positive effect of number of bad experiences is particularly interesting. It may reflect the fact that Next Generation Users make more intensive use of the Internet and so they are exposed to more bad experiences. The lack of a statistically significant effect for Internet ability may reflect the ease of use of apps and mobile devices in general. Mobile devices may not require Internet ability.

Most interesting is that once attitudes and skills are controlled, many of the demographic variables become non-significant. In particular, having a higher education degree, gender, being married and using the Internet at work are all clearly not significant. Age and income remain highly significant and being retired is also not influenced by the presence of the attitude and skills variables. This says that the effects of gender, education, and using the Internet at work are washed out by attitudes and skills. More specifically, as long as you have certain positive attitudes and certain skills, the education you have, your gender, your marital status or your use of the Internet at work have no effect on whether or not you become a Next Generation User. Interestingly, the same pattern of non-significance appears when we control for attitudes alone—without skills—or skills alone—without attitudes—(results not shown). The mechanism could be that technology attitudes make some people more (or less) receptive to new mobile devices. More receptive people are more likely to buy, learn, and use the devices. A similar mechanism may operate for skills: The more (fewer) skills may make 
people more (less) receptive to new devices. We can summarize these findings by saying that Next Generation Users are made by age, income, employment status, attitudes and skills.

\section{Beyond Britain: The World Internet Project}

Finally, while these detailed analyses are limited to Britain, our participation the WIP enables us to compare our findings with those of over two dozen other nations. ${ }^{12}$ From our work in this context, we have no evidence to question the generality of these basic patterns being applicable in other nations. In less well-to-do nations, for example, there has been less focus on the household as the main site of access, and more importance placed on shared locations, such as a cyber café. Likewise, some countries, such as Poland (WIP Poland 2011), have yet to see the rise in mobile and appliance-based access to the Internet that Britain, the US and many other nations have experienced. But those are some of the few differences and not findings that would raise doubts about the general conclusions of our analysis about the emergence of next generation users overtime, and the ways they have reconfigured their access to information, people, services, and technologies, such as appliances that complement other modes of access.

\section{The Future}

Clearly, more mobile phone users will be accessing the Internet in the coming years, but this forecast misses the broader picture - the twin trends of mobility and the use of multiple devices, and the synergy of these two trends that creates next generation use. As Figures 1 and 2 suggest, these trends appear to be strong and likely to continue into the foreseeable future. 
It is therefore important for research to begin to differentiate among Internet users in new ways. Speed remains one feature of new infrastructures that will shape patterns of access. But the days of narrow and broadband users are over, as nearly all users in Britain have some level of broadband access. Wireless access will also grow as more households have multiple and portable devices. It is because of wireless broadband access that portable devices are so capable of being used for accessing entertainment and information on the move. However, speed and wireless access are primarily enablers of new patterns of use and not the key factors discriminating among Internet users.

The central, new distinction - from the perspective of this study — is between first and next generation use. It will be important to track the growth of next generation use in relation to non-users, former users, and first generation users. Research needs to look at the consequences of next generation use on patterns of use and their societal implications. If, as we find, this next generation is truly empowering users in new ways, then it will be equally important to address the new digital divides created by the next generation users.

The key theoretical contribution of this study is to expose some problems of both technologically and socially deterministic perspectives. Innovations that define the next generation user are reconfiguring their access to information, people and services in ways that are likely to empower them in relation to other users. And those in school or work and with more schooling and higher incomes are more likely to have the skills and wherewithal to exploit this potential. However, this is in contradiction to the expectations of a technically dumb downed Internet, as quite the opposite appears to be emerging. New devices are complementing and building on existing tools. In contradiction to the domestication perspective, some people are better able to domesticate these new technologies than others, 
and the technologies tend to have systematic implications of their users, such an enabling them to integrate them into their lives in ways that enhance their significance.

This study exposes a curious contradiction in domestication research. On the one hand it claims to have its origins in an attempt to construct theory that avoids technological determinism (Silverstone 2006) and focuses on how people actually integrate technological objects into their lives. On the other hand most of the research focuses on individual objects, such as computers, mobile phones, and other ICTs. The complexity of the Internet shows the difficulty of this approach: on the Internet there is rarely a single "object". Next generation users do not focus on objects. Their purposes include finding entertainment, finding information, finding a job, or publishing their creative work.

To accomplish these ends they combine and integrate an ensemble of objects: smart phones, tablets, readers, laptops and desktops. For most people the objects are not the point. Their goal is most often not to "use my tablet"; instead, they want to listen to music or watch a movie. A fascination with the technology per se might have typified early hobbyists, and still some users of the Internet, but not most users. This understanding of how ICTs are used in service of people's goals is consistent with domestication research's emphasis on how people appropriate and domesticate an object, but it moves research away from a focus on the object to focus on the purposes that human beings wish to achieve through them.

One of the most remarkable aspects of the Internet is its dynamic. It has never the same object from year to year; for example, the dramatic rise in the use of social networking sites since 2007 has introduced a whole new way for people to communicate in large numbers. Another example: After more than a decade of languishing as "personal digital assistants" or 
PDAs, Apple introduced the iPad and newly renamed "tablets" suddenly became the Next Big Thing. The Internet is a site for multiple ICTs and multiple innovations. A weakness of domestication theory is that it assumes a certain level of stability, specifically that there is an identifiable and stable object that is slowly adapted to fit into the life of the household. But the Internet is not stable, but constantly being reinvented. Each new development has brought with it new challenges for people to incorporate into their routines. Continuing waves of innovation also challenge research. In the midst of continuing change the challenge is to identify patterns of incorporation that have stabilized and will persist for an extended period of time. Next generation users are the most recent of these patterns.

Other new research is also needed. Our survey data could well be complemented by more qualitative studies that would expand our understanding of next generation users to describe the meaning of these patterns of use to next generation users, how their identity is bound up in being a next generation user, how use is negotiated within households, and other topics that are difficult for survey research to address. 


\section{References}

American Association of Public Opinion Researchers. 2011. Standard Definitions: Final Dispositions of Case Codes and Outcome Rates for Surveys. $7^{\text {th }}$ edition. Available at http://www.aapor.org/Standard_Definitions/3049.htm downloaded on 2 September 2011.

Blank, Grant, and Dutton, William H. (2012), 'Age and Trust in the Internet: The Centrality of Experience and Attitudes Toward Technology in Britain', Social Science Computer Review: http://ssc.sagepub.com/content/early/2011/02/21/0894439310396186

Crampton, Jeremy W. 2004. The political mapping of cyberspace. Chicago: University of Chicago Press.

Danziger, James N., Dutton, William H., Kling, Rob, and Kraemer, Kenneth L. 1982. Computers and Politics: High Technology in American Local Governments, New York: Columbia University Press.

Dutton, William H. 1999. Society on the Line: Information Politics in the Digital Age, Oxford and New York: Oxford University Press.

Dutton, William H. 2005. 'The Internet and Social Transformation: Reconfiguring Access,' pp. 375-97 in Dutton, W. H., Kahin, B., O’Callaghan R., and Wyckoff, A. W. (eds.), Transforming Enterprise, Cambridge, MA: MIT Press.

Dutton, William H. and Grant Blank. 2011. Next generation users: The Internet in Britain. Oxford Internet Survey 2011. Oxford Internet Institute: University of Oxford.

Haddon, Leslie. 2006. The contribution of domestication research to in-home computing and media consumption. The Information Society. 22: 195-205.

Haddon, Leslie. 2007. Roger Silverstone’s legacies: domestication. New Media \& Society. 9: 25-32. 
Haddon, Leslie. 2011. Domestication analysis, objects of study, and the centrality of technologies in everyday life. Canadian Journal of Communication. 36:311-323.

King, Rachael. 2012. Great PC exodus on the Internet. ZDNet. Posted 29 October 2012. Accessed on 23/11/2012 from www.zdnet.com/idc-were-in-the-midst-of-the-great-pcexodus-on-the-internet-7000006532/

Lessig, Lawrence. 1999. Code and Other Laws of Cyberspace. New York: Basic Books. Livingstone, Sonia. 1992. The meaning of domestic technologies: A personal construct analysis of familial gender relations. Pp. 113-130 in Roger Silverstone and Eric Hirsch (eds.) Consuming technologies: Media and information in domestic spaces. London: Routledge.

Mayer-Schönberger, Viktor. 2008. 'Demystifying Lessig', Wisconsin Law Review , No. 4, 713-46.

Perlow, Jason. 2012. Post-PC means mass extinction for personal computer OEMs. ZDNet. Posted 31 May 2012. Accessed on 23/11/2012 from $\underline{\text { www.zdnet.com/blog/perlow/post-pc-era-means-mass-extinction-for-personal- }}$ computer-oems/20514

Punie, Yves. 1997. Rejections of ICT in Flemish households. The why-not question. Pp 4672 in Roger Silverstone and Maren Hartmann (eds). EMTEL working paper no. 3. Media and Information technology: Regulating markets \& everyday life. Brighton: University of Sussex.

Rogers, E. M. 1962. Diffusion of Innovations. New York: The Free Press.

Silverstone, R. 1996. Future Imperfect: Information and Communication Technologies in Everyday Life', pp. 217-31 in Dutton, W. H. (ed.), Information and Communication Technologies - Visions and Realities. Oxford: Oxford University Press. 
Silverstone, Roger. 2005. Introduction. Pp 1-18 in Roger Silverstone (ed) Media, technology and everyday life in Europe. Aldershot: Ashgate Press.

Silverstone, Roger. 2006. Domesticating domestication: Reflections on the life of a concept. pp. 229-248 in Thomas Berker, Maren Hartmann, Yves Punie and K. J. Ward (eds.). Domestication of media and technology. Berkshire: Open University Press.

Silverstone, Roger, Eric Hirsch, David Morley. 1992. Information and communication technologies and the moral economy of the household. Pp 15-31 in Roger Silverstone and Eric Hirsch (eds.) Consuming technologies: Media and information in domestic spaces. London: Routledge.

Wei, Ran. 2001. From luxury to utility: a longitudinal analysis of cell phone laggards. Journalism and Mass Communication Quarterly. 78:702-719.

WIP Poland (2011). World Internet Project Poland 2011. Warsaw, PL: Agora S.A. and TP Group.

Zittrain, Jonathan. 2008. The Future of the Internet and How to Stop It. New Haven: Yale University Press.

\section{Notes}

\footnotetext{
${ }^{1}$ The case for viewing Lessig's argument as technologically determinist is developed by Mayer-Schönberger (2008).
}
${ }^{2}$ These correspond to common stages in the adoption of an innovation, from adoption to implementation to routinization (Rogers 1962).
${ }^{3}$ For a more complete overview of the OxIS methodology, see: http://microsites.oii.ox.ac.uk/oxis/methodology

\footnotetext{
${ }^{4}$ Using response rate formula RR1 defined by the American Association of Public Opinion Researchers (AAPOR) (2011:44).
} 
${ }^{5}$ For a more detailed description of the sample and methodology see Dutton and Blank (2011).

${ }^{6}$ For example, Wei's (2001) study of mobile phones.

${ }^{7}$ The four applications are: browsing the Internet, using email, updating a social networking site, or finding directions.

${ }^{8}$ Interestingly, education does not have a zero-order effect on being a Next Generation User. See below for the effect in a multivariate model.

${ }^{9}$ The variables are defined as age, a continuous variable ranging from 14-92 years; income, an 8 category variable; higher education degree, a dummy variable indicating whether or not a respondent has a higher education degree; gender, a dummy variable using males as the comparison group; retired, a dummy variable indicating retired people; use the Internet at work, a dummy variable indicating if the respondent uses the Internet in their job; and married, a dummy variable indicating the respondent is married. We also tried a variable measuring urban-rural residence but it was not statistically significant. For several variables in the model we tried numerous specifications. For marital status the full variable had five categories, but only the 'married' category was statistically significant. Similarly, for education only the higher education category was significant, and for 'life stage' only 'retired' was significant.

${ }^{10}$ Strength is measured by the size of the odds ratio. With an odds ratio of only 0.33 , retired respondents are the most important variable in the regression. Similarly, having a higher education degree and using the Internet at work both have odds ratios near 1.50, making them the second most important variables in the regression.

${ }^{11}$ Note, however, that when we substituted a direct measure of occupation in this model it was not statistically significant.

${ }^{12}$ Information about the World Internet Project (WIP) and other national samples can be found online at: http://www.worldinternetproject.net/\#news 